\title{
Research on the Calculation Method of Skeleton Curve of Variable Cross Sectional Concrete Filled Steel Tubular Laced Columns with Flat Lacing Tube
}

\author{
Zhijing OU \\ College of Civil Engineering \\ Fujian University of Technology \\ Fuzhou, China \\ e-mail: sina99@163.com
}

\author{
Shengfu CHEN \\ College of Civil Engineering \\ Fujian University of Technology \\ Fuzhou, China \\ e-mail: 280460976@qq.com \\ Jianmao LIN \\ College of Civil Engineering \\ Fujian University of Technology \\ Fuzhou, China \\ e-mail:924697140@qq.com
}

\begin{abstract}
Variable cross-sectional Concrete Filled Steel Tubular (CFST) laced column with flat lacing tube is a kind of emerging combination column; it has broad application prospects in high pier bridges and high-rise buildings. The finite element analysis method of CFST laced columns is built with universal program of OpenSEES, and the influence of structural parameters on seismic performance of CFST laced columns is researched. Then the calculation method of skeleton curve of variable cross-sectional CFST laced columns is studied referencing the computing framework of hysteretic model of CFST single tube column and equal sectional laced column, the calculation formula of elastic stiffness, horizontal peak load and its displacement, fall-period stiffness are developed respectively. Engineering examples verifications of Gan haizi bridge's laced column pier are processed with OpenSEES program, and research results indicated that the calculated values are coincident well with numerical results. Finally a rational method to calculate the skeleton curve of variable cross-sectional CFST laced columns with flat lacing tube is provided on the basis of the analytical results.
\end{abstract}

Keywords-variable cross-sectional; concrete filled steel tube column; flat lacing tube; skeleton curve; calculation method

\section{INTRODUCTION}

Concrete filled steel tubular (CFST) laced columns are widely used as building columns and as elements in arch bridges [1] [2]. Compare with equal sectional laced column, variable cross-sectional laced columns (the section size of column is gradually increasing from top to bottom) is advantageous in relatively high compressive strength, capacity, relatively high horizontal bearing capacity, good overall stability, excellent deformation capacity and attractive appearance. Furthermore, this type of hybrid column has more excellent earthquake resistance for its center of gravity is lower and the reaction of the column under earthquake function is decreased [3]. In recent years, variable cross-sectional laced columns with flat lacing tube was found to be applied in high-pier bridges located in strong earthquake region, and it has become one of the most potential pier forms. For example, combination column of this type was used in Ganhaizi super large bridge in Sichuan province, the largest laced column pier is 67.29 meters high.

Skeleton curve is a key quota to study the seismic behavior of concrete filled steel tubular columns, and it is also an important basis to determine the characteristic points of the restoring force model. In recent years, many research work on skeleton curve of CFST single-tube column have been carried out and effective algorithms are proposed[4]. Meanwhile, some experimental study on hysteretic behavior of equal sectional laced column have been done (including two-element and four-element type), and the corresponding calculation formula of skeleton curve has been proposed on the base of finite element analysis results [5]-[8]. However, seldom research has been conducted on aseismic behavior of variable cross-sectional CFST laced columns, and there is an urgent need of calculation method on skeleton curve.

In this paper, a parametric study of the seismic performance of variable cross-sectional CFST laced columns by using the OpenSEES finite-element analysis program was performed. On the basis of the findings, the calculation methods of key parameters of skeleton curve are discussed. Finally a universal method that can accurately predict the skeleton curve of four-tube variable cross-sectional CFST laced columns with flat lacing tube is proposed by reference to calculation formula of CFST single tube column and same cross-sectional laced columns.

\section{FINITE ELEMENT ANALYSIS OF SEISMIC BEHAVIOR}

A parametric study of the seismic performance of variable cross-sectional CFST laced columns by using the OpenSEES finite-element analysis program was performed referencing the modeling method in Refs, 8.

Fiber element method is adopted in finite element modeling, and element type is dispBeamColumn element. The effect of P-Delta should be taken into account in local direction coordinates of members. The bottom of laced column keeps consolidation, and displacement control method is used to simulate quasi-static loading test.

Standard specimen is named BP-0(shown in Fig.1), it is modeled as Ganhaizi super bridge and the scale is $1: 10$. The 
height of column is $2.5 \mathrm{~m}$, the slope of longitudinal element is $1: 40$, and axial compression ratio is 0.15 . Elastic modulus of steel and concrete is $2.06 \times 10^{5} \mathrm{Mpa}$, and $3.45 \times 10^{4} \mathrm{MPa}$, respectively. Specified yield strength of steel $=345 \mathrm{MPa}$ and compressive strength of concrete $=38 \mathrm{MPa}$. More information about the nonlinear material properties used in this study can be found in Refs, 4 and Refs, 9 .

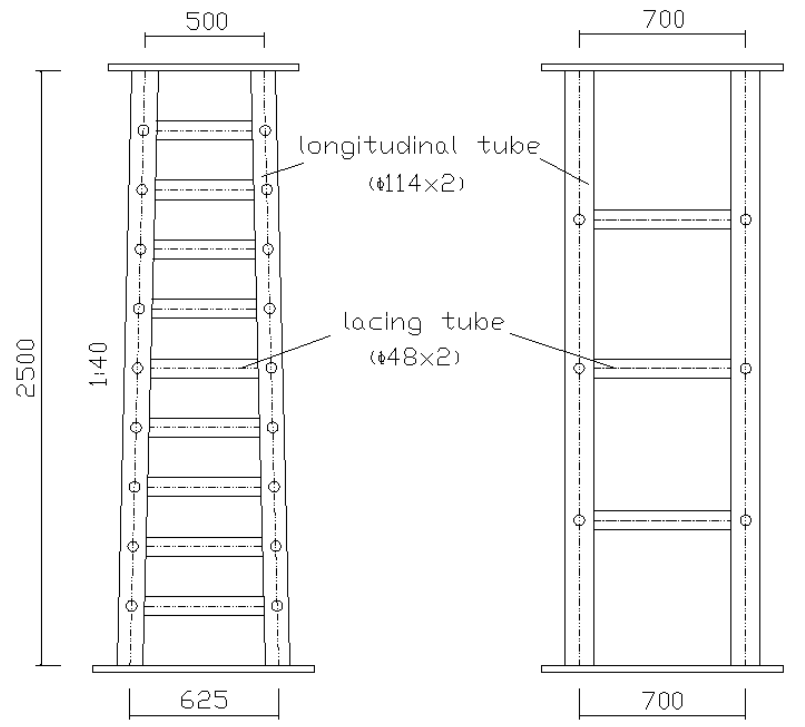

Figure 1. Configuration of specimen BP-0 (unit:mm)

The variation range of parameters of 44 specimens are presented as follows: the slope of longitudinal element is varied from $1: 70$ to $1: 20$, axial compression ratio is varied from 0.1 to 0.5 , the length of column is varied from $2.5 \mathrm{~m}$ to $15 \mathrm{~m}$, vertical spacing of flat lacing tubes is varied from 0.125 to $0.5 \mathrm{~m}$, steel ratio of longitudinal element is varied from $4 \%$ to $19 \%$, diameter ratio of lacing tubes and longitudinal tubes is varied from 0.2 to 0.8 , yield strength of steel is varied from 240Mpa to480Mpa, concrete label is varied from C30 to C70.

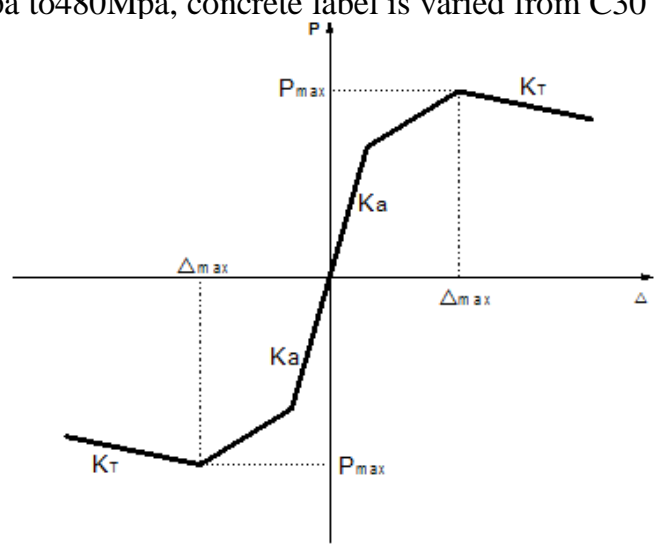

Figure 2. Key parameter of typical skeleton curve

Through the numerical calculation of these specimens, typical skeleton curve is obtained in Fig.2. Here, $K_{\mathrm{a}}$ is elastic stiffness, $P_{\max }$ is horizontal peak load, $\Delta_{\max }$ is displacement on peak load, $K_{\mathrm{T}}$ is fall-period stiffness. Then the influence rules of parameters on skeleton curve of laced columns are researched, shown in Tab.1.

TABLE I. KEY PARAMETERS ON SKELETON CURVE OF CFST LACED COLUMN

\begin{tabular}{lcccc}
\hline Parameter & $\mathrm{K}_{\mathrm{a}}$ & $\mathrm{P}_{\max }$ & $\Delta_{\max }$ & $K_{\mathrm{T}}$ \\
\hline Slope of longitudinal element & $\nearrow$ & $\nearrow$ & - & $\nearrow$ \\
Axial compression ratio & - & $\searrow$ & $\searrow$ & $\nearrow$ \\
Length of laced column $\nearrow$ & $\searrow$ & $\searrow$ & $\nearrow$ & $\searrow$ \\
Vertical spacing of lacing tubes & $\searrow$ & $\searrow$ & - & - \\
Diameter ratio of tubes $\nearrow$ & $\nearrow$ & $\nearrow$ & - & $\nearrow$ \\
Steel ratio $\nearrow$ & $\nearrow$ & $\nearrow$ & - & $\nearrow$ \\
Concrete strength $\nearrow$ & - & $\nearrow$ & - & - \\
Yield strength of steel & & & & \\
\hline
\end{tabular}

\section{CAlCUlation OF ChaRACTERISTIC VAlue OF SKELETON CURVE}

Comparing the numerical results and research results in Refs, 4 through Refs, 8, it can be found that the influence rule of main parameters on CFST column is similar. So the calculation method of skeleton curve of variable cross-sectional CFST laced columns will be studied referencing the computing framework of hysteretic model of CFST single tube column and equal sectional laced column.

\section{A. Elastic Stiffness $\left(K_{a}\right)$}

The elastic stiffness of CFST single tube column can be calculated as Eq.1 [4].

$$
K_{a}=\frac{3 K_{e}}{\left(L_{0}\right)^{3}}=\frac{3\left(E_{s} I_{s}+0.6 E_{c} I_{c}\right)}{\left(L_{0}\right)^{3}}
$$

Where $K_{a}$ is elastic stiffness, $K_{e}$ is elastic stiffness Flexural rigidity, LO is the length of CFST single tube column, $E_{s}$ and $E_{c}$ are Elastic modulus of steel and concrete, $I_{s}$ and $I_{c}$ are Moment of inertia of longitudinal steel tube and core concrete, respectively.

It is suggested that Eq. 1 can be rewritten into Eq. 2 in the calculation of elastic stiffness $\left(K_{\mathrm{a}}\right)$ of variable cross-sectional CFST laced columns with flat lacing tube. Here, $g$ denotes equivalent length factor (which can be obtained by Eq. 3 and Eq.4 [10] [11]), and $\mathrm{K}$ denotes equivalent slenderness ratio factor (which can be obtained by Eq.5 and Eq.6). Firstly variable cross-sectional CFST laced column with the length of $\mathrm{L}$ will equivalent to equal sectional laced column with the length of gL (their top section is same), then equal sectional laced column can be equivalent to single tube column with 
the length of $\mathrm{KgL}$.

$$
\begin{gathered}
K_{a}=\frac{3\left(E_{s} I_{s}+0.6 E_{c} I_{c}\right)}{(g K L)^{3}} \\
g=1-0.375 \gamma+0.08 \gamma^{2}(1-0.0775 \gamma) \\
\gamma=(2 * \theta * L) / d_{0} \\
K=\sqrt{1+6 \mu} \\
\mu=\frac{1}{2}\left(\frac{b}{\mathrm{gL}}\right)^{2}\left(3.83 \frac{A_{d}}{A_{b}}\right)
\end{gathered}
$$

Where $\gamma^{\gamma}$ is section enlargement factor, $K_{e}$ is flexural rigidity, $\theta$ is the slope of longitudinal element, $d_{0}$ is width of top section of laced column, $\mu$ is shear flexibility coefficient, $\mathrm{b}$ is plane center distance of longitudinal element, $A_{d}$ and $A_{b}$ are equivalent area of single longitudinal element and area of single flat lacing tube, respectively.

According to this method, the comparison of calculation values of elastic stiffness $\left(K_{\mathrm{a}}\right)$ and numerical values by OpenSEES program for 44 specimens are shown in Fig.3. It can be found that calculation results coincided very closely with the numerical results. The average ratio (calculated value/ numerical value) is 1.028 .

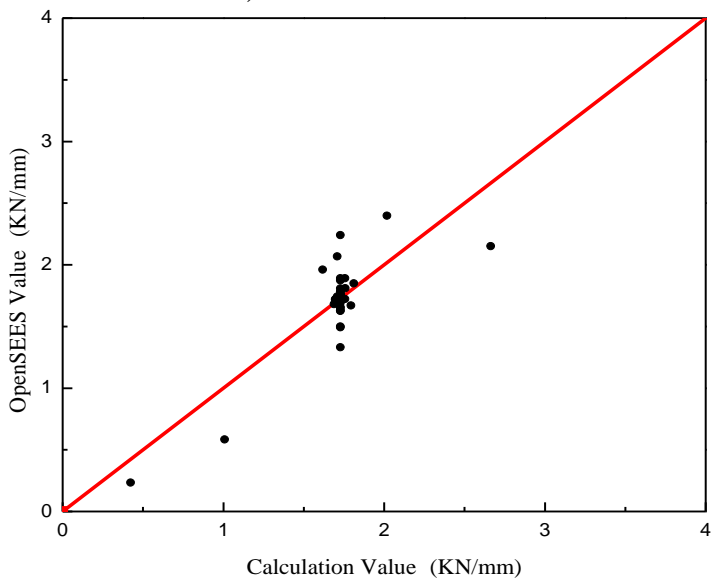

Figure 3. Comparison of $K_{a}$ of CFST laced columns

\section{B. Horizontal Peak Load $\left(P_{\max }\right)$}

It is suggested that horizontal peak load $\left(\mathrm{P}_{\max }\right)$ of variable cross-sectional CFST laced column can be calculated by Eq.7, referring to the formula of CFST equal sectional laced column [8] and single tube column [4].

$$
P_{\max }=\sqrt{\left(1-n^{2}\right)} \frac{M_{0}}{2 \mathrm{~g} L}
$$

Where ${ }^{n}$ is axial compression ratio, $M_{0}$ is Moment bearing capacity, $\mathrm{g}$ is equivalent length factor, and $\mathrm{L}$ is the length of laced column. $M_{0}$ can be obtained by using Eq.8 to Eq.11.

$$
\begin{gathered}
M_{0}=\left(\gamma_{m} W_{s c m} f_{s c y}\right) \\
\gamma_{m}=1.04+0.48 \ln (\xi+0.1) \\
W_{s c m}=\left(A_{s}+A_{c}\right) \times r \times 4
\end{gathered}
$$

$$
f_{s c y}=\frac{N_{0}}{S}=\frac{N_{0}}{b \times c}
$$

Where ${ }^{\gamma_{m}}$ is coefficient of bending strength, $\xi$ is Hoop factor, $W_{s c m}$ is section bending modulus, $A_{s}$ and $A_{c}$ are area of longitudinal tube and concrete, respectively, $r$ is turning radius of laced column, $f_{s c y}$ is coefficient of composite compressive strength, $N_{0}$ is ultimate load of laced column , b and c are center distance of longitudinal element in plane and out of plane, respectively.

In order to verify this method, comparison of calculation values of horizontal peak load $\left(\mathrm{P}_{\max }\right)$ and numerical values by OpenSEES program for 44 specimens are shown in Fig.4. It can be found that calculation results coincided well with the numerical results. The average ratio (calculated value/ numerical value) is 0.990 .

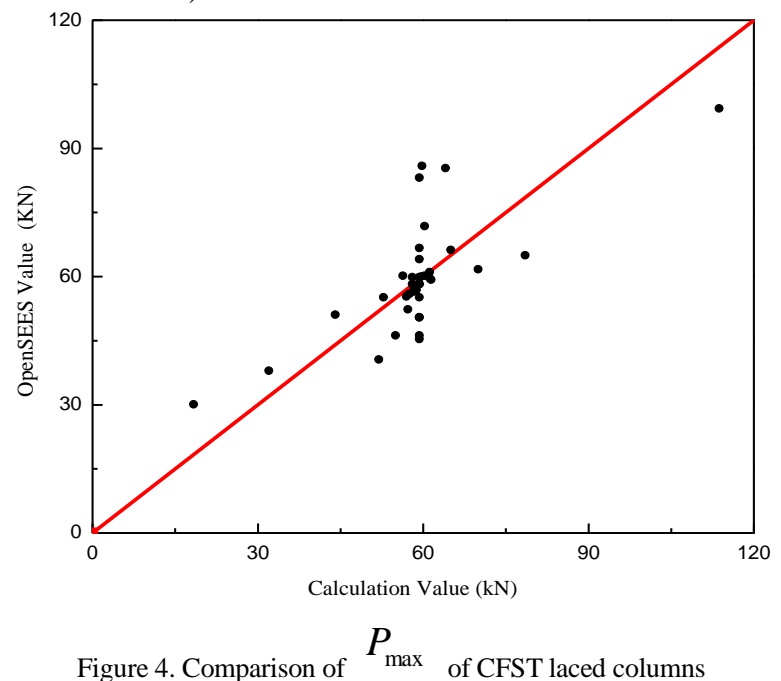




\section{Displacement at Peak Load $\left(\Delta_{\max }\right)$}

According to Tab.1, it can be found that axial compression ratio (n), the length of column (L) and yield strength of steel are key parameters which have important influence on displacement at peak load $\left(\Delta_{\max }\right)$. This rule is similar to CFST single tube column. So it is suggested that $\Delta_{\max }$ of variable cross-sectional CFST laced column can be calculated by Eq.12, referring to the formula of CFST single tube column [4].

$$
\Delta_{\max }=K_{p} \cdot \frac{P_{\max }}{K_{a}}
$$

Where $\mathrm{K}_{\mathrm{p}}=$ amplification factor of peak displacement, it is relate to three parameters mentioned earlier and can be expressed by using Eq.13. Here, $\lambda^{*}$ is equivalent slenderness, it can be obtained by Eq.14.

$$
\begin{gathered}
K_{p}=\left(2.8-n-0.03 \times \lambda^{*}\right) \times\left(\frac{345}{f_{y}}\right) \\
\lambda^{*}=g K \lambda
\end{gathered}
$$

According to this method, the comparison of calculation values of peak displacement $\left(\Delta_{\max }\right)$ and numerical values by OpenSEES program for 44 specimens are shown in Fig.5. It can be found that calculation results coincided well with the numerical results. The average ratio (calculated value/ numerical value) is 1.090 .

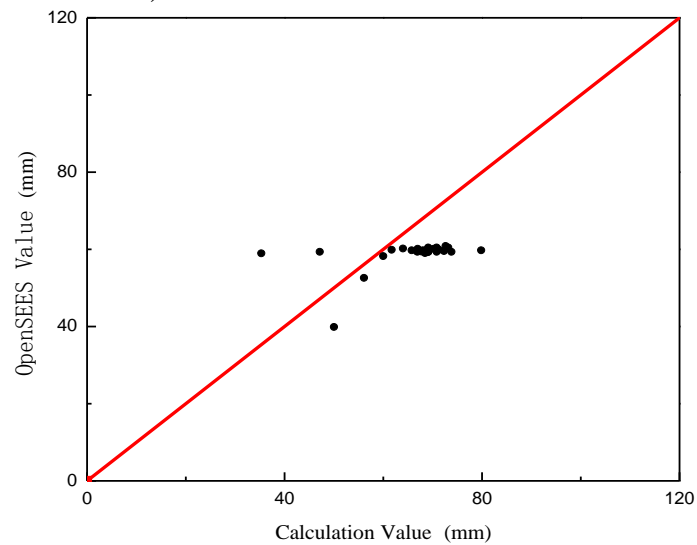

Figure 5. Comparison of $\Delta_{\max }$ of CFST laced columns

\section{Fall-period Stiffness $\left(K_{T}\right)$}

Numerical analysis indicated that the main parameters which have a certain influence on the fall-period stiffness $\left(\mathrm{K}_{\mathrm{T}}\right)$ of variable cross-sectional CFST laced column's skeleton curve are $\mathrm{n}, \lambda^{*}$ and fy. This rule is similar to CFST single tube column. Therefore, $\mathrm{K}_{\mathrm{T}}$ can be calculated by Eq.15, referring to the formula of CFST single tube column [4].

$$
K_{T}=\frac{-9.83 f(n) \lambda^{* 0.75} f_{y}}{E_{s} \xi} K_{a}
$$

According to research findings on parameter analysis, it is indicated that fall-period stiffness $\left(\mathrm{K}_{\mathrm{T}}\right)$ will increase gradually with the increase of axial compression ratio (n) when $\mathrm{n}$ is lower than 0.4 , and when $\mathrm{n}$ is larger than 0.4 , the effect of $n$ on $K_{T}$ is relatively small. So the value of $f(n)$ can be calculated by using Eq.16 depending on the scope of $n$.

$$
f(n)= \begin{cases}n+0.35 & (n \leq 0.4) \\ 1 & (n>0.4)\end{cases}
$$

According to this method, the comparison of calculation values of fall-period stiffness $\left(\mathrm{K}_{\mathrm{T}}\right)$ and numerical values by OpenSEES program for 44 specimens are shown in Fig.6. It can be found that calculation results coincided well with the numerical results. The average ratio (calculated value/ numerical value) is 0.90 .

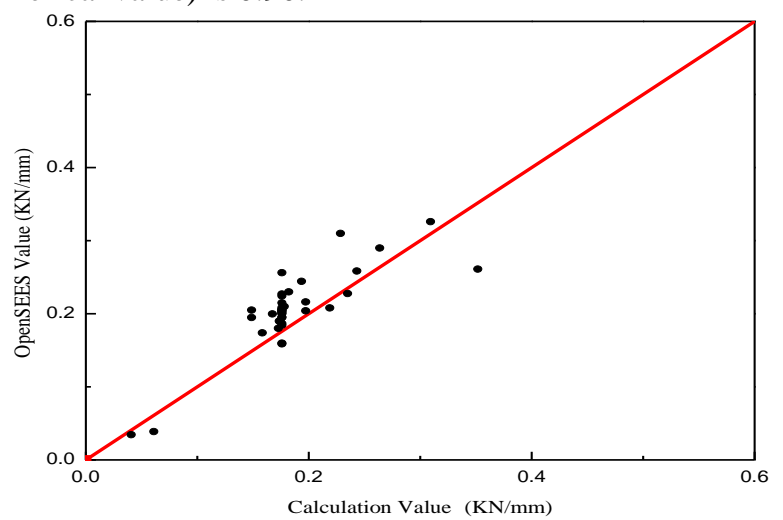

Figure 6. Comparison of $K_{T}$ of CFST laced columns

\section{CALCUlation Method VAlidation}

In order to verify the rationality of calculation method of skeleton curve in this paper, pier 2 of Ganhaizi Bridge in Yaxi expressway was chosen as research object. Pier 2 is four-element variable cross-sectional CFST laced column with flat lacing tube, and three steel pipe trusses are placed between longitudinal elements in bridge width direction to strengthen the whole stiffeners of piers.

The height of this laced column is $24 \mathrm{~m}$, the slope of longitudinal element is 1:50, and axial compression ratio is 0.15 . Plane center distance of longitudinal element is $1.15 \mathrm{~m}$ at top section, and the distance at bottom section is $2.11 \mathrm{~m}$. Center distance of longitudinal element out of plane is $12.25 \mathrm{~m}$. Vertical spacing of flat lacing tube is $2 \mathrm{~m}$. Outside diameter and thickness of longitudinal tube are $813 \mathrm{~mm}$ and $12 \mathrm{~mm}$, respectively. Outside diameter and thickness of lacing tube are $406 \mathrm{~mm}$ and $10 \mathrm{~mm}$, respectively. The elastic modulus of steel and concrete is $2.06 \times 10^{5} \mathrm{Mpa}$ and $3.45 \times 10^{4} \mathrm{MPa}$, respectively. Specified yield strength of steel $=345 \mathrm{MPa}$, and compressive strength of concrete $=38 \mathrm{MPa}$. 


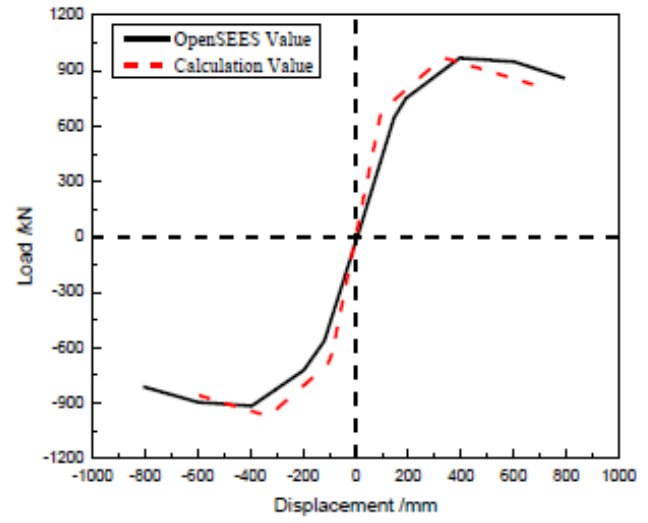

Figure 7. Comparison of skeleton curves

The comparison of skeleton curve calculated by the method in this paper and by OpenSEES program for Pier 2 is shown in Fig.7. It can be found from Fig.7 that two skeleton curves are very close, that is, calculation results coincided well with the numerical results. So this calculation method on skeleton curve is verified to be reasonable for variable cross-sectional CFST laced column with flat lacing tube.

\section{CONCLUSIONS}

In this analytical investigation, four-tube variable cross-sectional CFST laced column whit flat lacing tube was investigated and recommendations are provided to calculate the skeleton curve. On the basis of these results, the following general conclusions were obtained:

- A finite-element modeling scheme was used to perform a parametric study. Then the influence rule of parameters on the skeleton curve was obtained. This rule is similar with CFST single tube column and equal sectional laced column.

- According the finding of parametric study, formula of key parameters on skeleton curve is proposed referencing the CFST single tube column and equal sectional laced column.

- Finally a practical method to calculate the skeleton curve of variable cross-sectional CFST laced column with lacing tube was developed (shown in Tab.2) on the basis of the finite-element analysis and the engineering example verification.

TABLE II. Calculation Method of SKeleton CuRVE of Variable CROSS-SECTIONAL CFST LACED COLUMN WITH LACING TUBE

\begin{tabular}{cc}
\hline Parameter & Calculation formula \\
\hline$K_{a}=\frac{3\left(E_{s} I_{s}+0.6 E_{c} I_{c}\right)}{(K g L)^{3}}$ & $g=1-0.375 \gamma+0.08 \gamma^{2}(1-0.0775 \gamma)$ \\
Elastic stiffness & $\gamma=(2 * \theta * L) / d_{0}$ \\
$K_{\mathrm{a}}$ & $K=\sqrt{1+6 \mu}$ \\
$\mu$ & $=\frac{1}{2}\left(\frac{b}{\mathrm{gL}}\right)^{2}\left(3.83 \frac{A_{c}}{A_{b}}\right)$ \\
\hline
\end{tabular}

\begin{tabular}{|c|c|}
\hline $\begin{array}{l}\text { Horizontal peak load } \\
P_{\max }\end{array}$ & $\begin{aligned} P_{\max } & =\sqrt{\left(1-n^{2}\right)} \frac{M_{0}}{2 \mathrm{~g} L} \\
M_{0} & =\alpha \gamma_{m} W_{s c m} f_{s c y}\end{aligned}$ \\
\hline $\begin{array}{c}\text { peak displacement } \\
\Delta_{\max }\end{array}$ & $\begin{array}{c}\Delta_{\max }=K_{p} \cdot \frac{P_{\max }}{K_{a}} \\
K_{p}=\left(2.8-n-0.03 \times \lambda^{*}\right) \times\left(\frac{345}{f_{y}}\right)\end{array}$ \\
\hline fall-period stiffness $K_{\mathrm{T}}$ & $\begin{array}{r}K_{T}=\frac{-9.83 f(n) \lambda^{0.75} f_{y}}{E_{s} \xi} K_{a} \\
f(n)= \begin{cases}n+0.35 & (n \leq 0.4) \\
1 & (n>0.4)\end{cases} \end{array}$ \\
\hline
\end{tabular}

\section{ACKNOWLEDGEMENT}

This research work has been conducted under the grant number 51408128 of the national natural science foundation of China and the grant number GY-Z15108 of the program for new century excellent talents in Fujian Province university. This support is sincerely appreciated.

\section{REFERENCE}

[1] Cai Shaohuai. Modern steel tubular Confined concrete structures [M]. Beijing: China Communications Press, 2003. (in Chinese)

[2] Chen Baochun. Concrete Filled Steel Tubulur Arch Bridges [M], Beijing: China Communications Press, 2007. (in Chinese)

[3] Zhijing Ou .The Practice of Concrete Filled Steel Tube Piers to Bridges: A review [J], Applied Mechanics and Materials, Vols.405-408, pp1602-1604, 2013.

[4] Han Linhai. The concrete filled steel tubular structures from theory to practice [M], Beijing: Science Press, 2004. (in Chinese)

[5] Kawano A, Matsui C. The Deformation Capacity of Trusses with Concrete Filled Tubular Chords [C]. Proceedings of The Conference of Composite Construction in Steel and Concrete IV. Banff Alta, Canada, 2000: 734-745.

[6] Deng Xuanyi. Study on the seismic performance of concrete filled steel tubular lattice column [D]. Central South University, 2012. (in Chinese)

[7] Luo Yao. Studies on the seismic performance of four-tube concrete filled steel tubular laced columns [D]. Central South University, 2013. (in Chinese)

[8] Lv Yinhua.Studies on hysteretic behavior of uniform section concrete filled steel tubular laced columns with flat lacing tube [D]. Fuzhou University, 2015. (in Chinese)

[9] Menegotto M, Pinto P E. Method of Analysis for Cyclically Loaded Reinforced Concrete Plane Frames Including Changes in Geometry and Non-elastic Behavior of Elements Under Combined Normal Force and Bending $[\mathrm{C}]$. Proceedings, IABSE Symposium on Resistance and Ultimate Deformability of Structural Acted on by Well-Defined Repeated Loads, Lisbon, 1973: 15-22.

[10] Galambos TV. Guide to stability design criteria for metal structures [M]. New York: John Wiley \&Sons, Inc, 1998. [7] Galambos TV. Guide to stability design criteria for metal structures [M]. New York: John Wiley \&Sons, Inc, 1998: 83-87.

[11] LRFD, (1999). Specification for structural steel buildings, American institute of steel construction (AISC), Chicago, IL. 